Education \& Training | Markus Talvio \& Kirsti Lonka

\section{Lions Quest}

Promoting social and emotional learning in the classroom

\begin{tabular}{|c|c|}
\hline $\begin{array}{l}\text { The positive psychology } \\
\text { movement promotes positivity } \\
\text { and support in the classroom, } \\
\text { to increase students' well-being } \\
\text { and academic achievement. } \\
\text { Teachers are ideally placed to } \\
\text { deliver this support. However, } \\
\text { their skills and competencies in } \\
\text { social and emotional learning } \\
\text { (SEL) need to be developed. } \\
\text { Dr Markus Talvio and Prof Kirsti } \\
\text { Lonka conducted research into } \\
\text { SEL interventions, particularly } \\
\text { Lions Quest teacher } \\
\text { workshops, which aim to } \\
\text { develop skills in SEL. Following } \\
\text { their research, the authors } \\
\text { developed an intervention } \\
\text { protocol to enhance teachers' } \\
\text { professional development } \\
\text { and competencies in SEL and, } \\
\text { ultimately, develop classroom } \\
\text { cultures that promote well- } \\
\text { being and academic flourishing } \\
\text { in both teachers and students. }\end{array}$ & $\begin{array}{l}\text { n recent years, research has shown } \\
\text { that students' well-being and } \\
\text { academic achievement are promoted } \\
\text { in a classroom that supports a } \\
\text { positiviva atmosphere and constructive } \\
\text { interactions. This is one of the key } \\
\text { principles of the positive psychology } \\
\text { movement. Teachers, who spend the } \\
\text { most time with students at school in the } \\
\text { classroom, are crucial to developing } \\
\text { an engaging and supportive learning } \\
\text { environment. Social and emotional } \\
\text { learning (SEL) is instrumental in creating } \\
\text { the appropriate surroundings and } \\
\text { fostering good relationships between } \\
\text { teachers and students. } \\
\text { SOCIAL AND } \\
\text { EMOTONAL LEARNING } \\
\text { SEL is an all-encompassing approach to to } \\
\text { promoting positive life development. } \\
\text { It helps students develop the skills } \\
\text { to create good relationships with } \\
\text { themselves and with thers. To enable } \\
\text { teachers to support this development, } \\
\text { they themselves need to have good } \\
\text { social and emotional competence to } \\
\text { be able to interact with students in a } \\
\text { supportive and respectful way. After } \\
\text { all if if ctudents are totake on hord }\end{array}$ \\
\hline
\end{tabular}

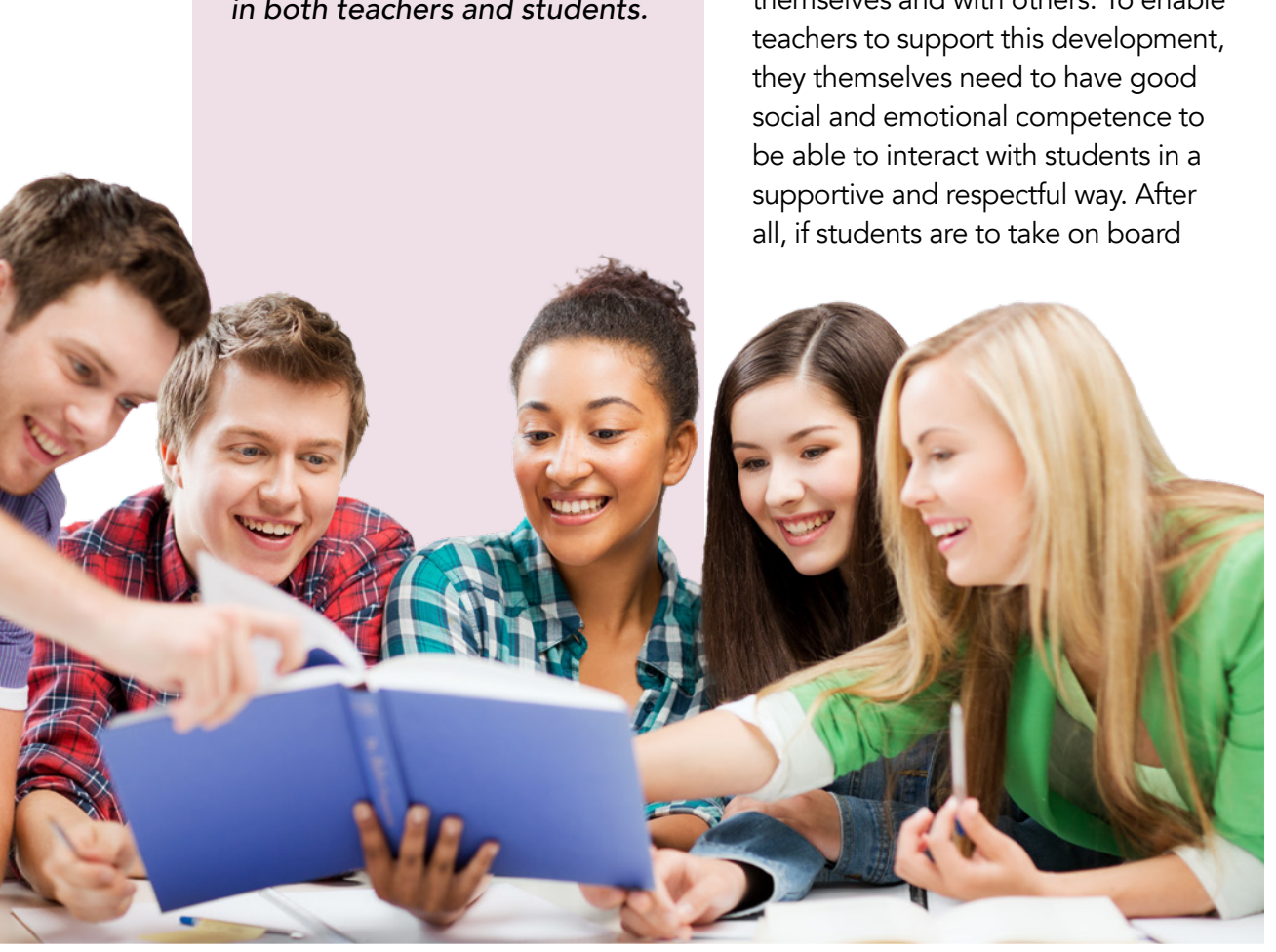

the importance of respect for others and for themselves, then this must be reflected in the way their teachers interact with them. Currently, however core teacher training around the world rarely includes any SEL elements. There are a number of additiona programmes offered as part of (CPD) that do offer training in SEL (httrs://caselorgh but litle resear been done into how teachers benefit from this training.

\section{LIONS QUEST} SEL programme that is available today in over 105 countries and has been running over 30 years. Over 18 million students have participated in $\mathrm{LQ}$, with more than half a million teachers implementing LQ in their classrooms. Teachers are required to participate in the $L Q$ teacher workshops that provide the tools necessary to implement $L Q$ in classrooms. In addition to promoting SE cklls in the classroom, LQ promotes the

Originally developed to prevent drug and alcohol abuse, it was found that life skills such as social interaction not only help prevent substance abuse but also develop healthy and capable adults. substance awareness, life skills are seen as important in their own right, not only as tools to prevent drug use. There is a strong anti-bullying message behind the programme, as well as an emphasis on connection to school, positive behaviour, character development and service-learning. These are all importan 政

n order to learn more about how teachers are implementing $L Q$ in other countries and to improve training cources, Lions Quest Internation implementation of $\mathrm{O}$ and training in several countries. Dr Markus Talvio, principal researcher for the project, and Professor Kirsti Lonk research supenvisor, used this research to develop a protocol to enhance teachers' professional development and competencies in SEL. They collected data from nine countries to evaluate how teachers' thinking changed during SEL training and to assess whether the effects of the training lasted over time.

The overall aim of the research was principally to clarify the benefits of the LQ workshops for teachers, and to use the findings to improve teach will ensure that the programme is optimally implemented to better support young people.

In addition to investigating the effectiveness of $L Q$ workshops, the researchers also looked at Gordon's Teacher Effectiveness Training (TET) and evaluated the effectiveness of TET workshops. Thomas Gordon has been central to interventions aiming to foster positive interactions in the classroom. Based on the humanistic psychology movement of the 1960s, Gordon's models emphasised the importance of using individual resources and adoptin respectill alfude towads others.

\section{EVALUATING SEL TRAINING} Taking place from 2013 to 2019, the $Q \mathrm{Q}$ was conducted in three stages?

The goal of Phase I was to develop and test a training evaluation model for the International LQ Evaluation Project. The participants were teachers in Finland. The results from this phase showed that participating teachers rated the $L Q$ goals as more important and relevant after receiving training and they felt more competent in skills related to LQ.

In Phase II, the development of teachers' social and emotional intelligence was investigated. Changes in teachers' skills during the knowledge, and explored, and data from nine countie

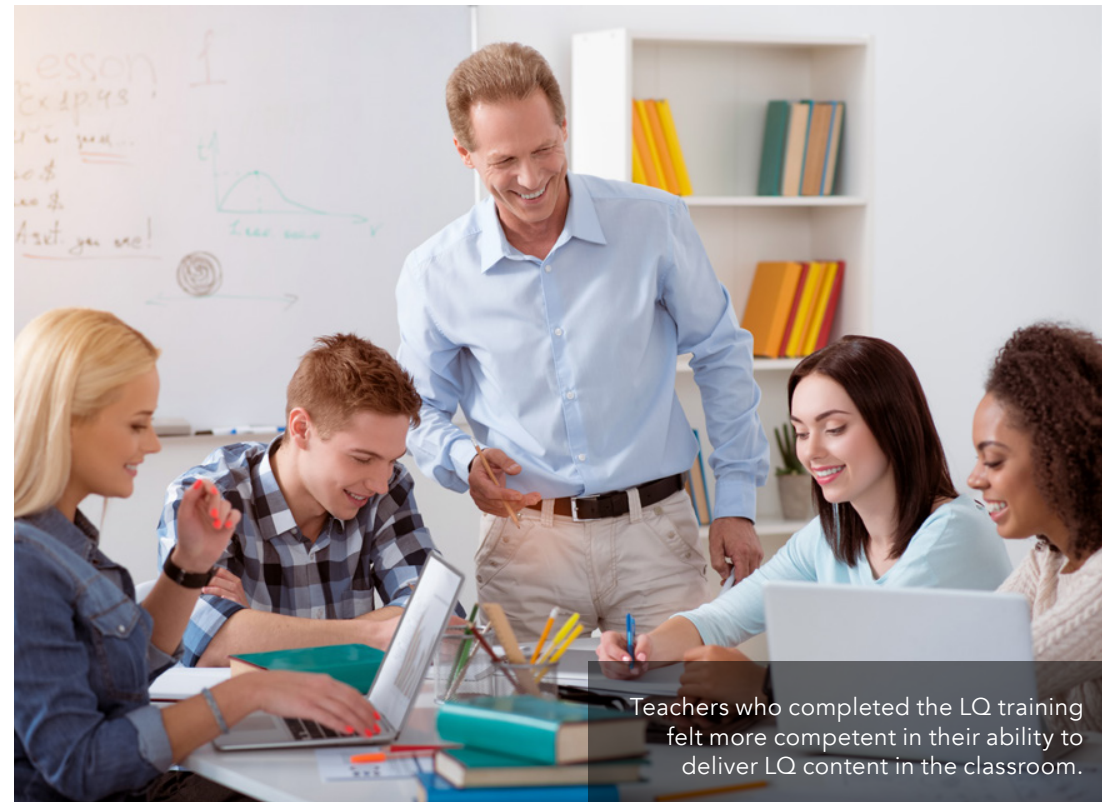

Teachers are crucial to

developing an engaging and supportive learning environment.

comprising workshops from ten areas were collected. Results from Finland Italy, Japan and Lithuania from 940 teachers in 2015-2016 showed that they perceived the LQ goals as more teachers' workshop. They also felt more competent in their ability to deliver $L Q$ content in the classroom setting. Final results from further data collected from Argentina, Australia, Austria, Germany and Turkey, and longitudinal data

participated in the $L Q$ training increased
their skills and knowledge and had more positive attitudes towards the LQ goals.

In Phase III of the research into the effectiveness of $L Q$ workshops,

results were disseminated and

recommendations for the future have been made. The team have led semina in participating countries, published scienticic articles to share the data with pronference and exhibition scivint

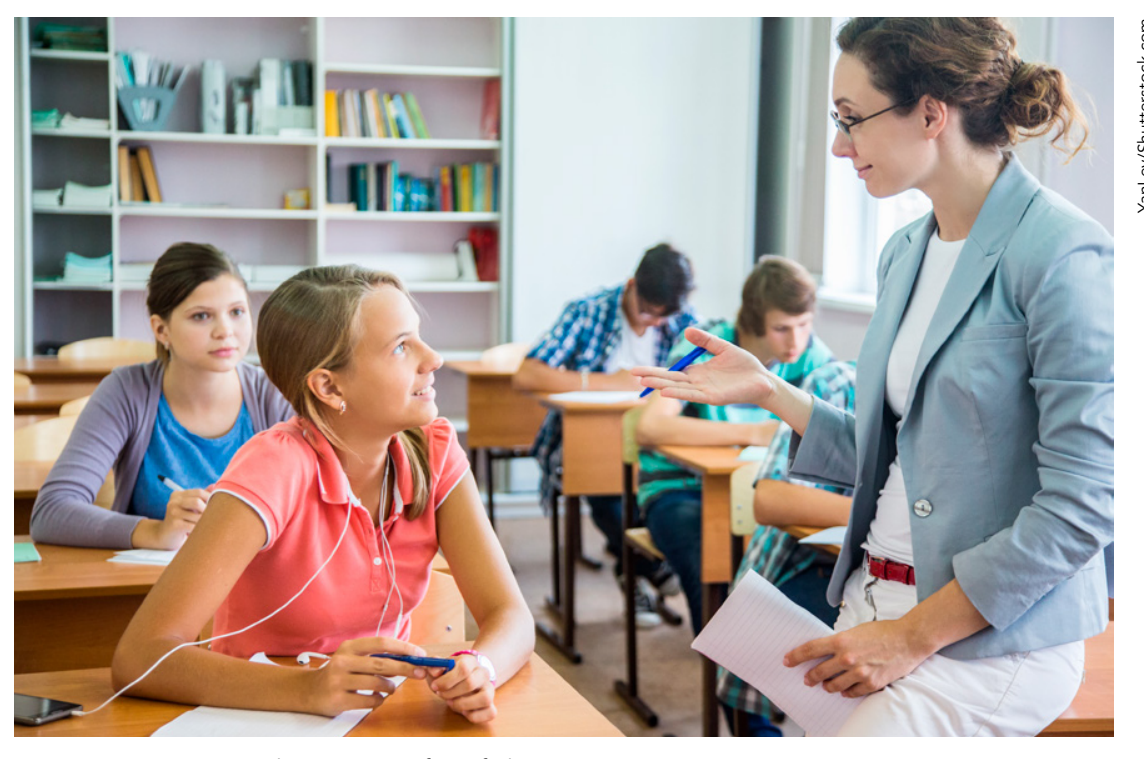




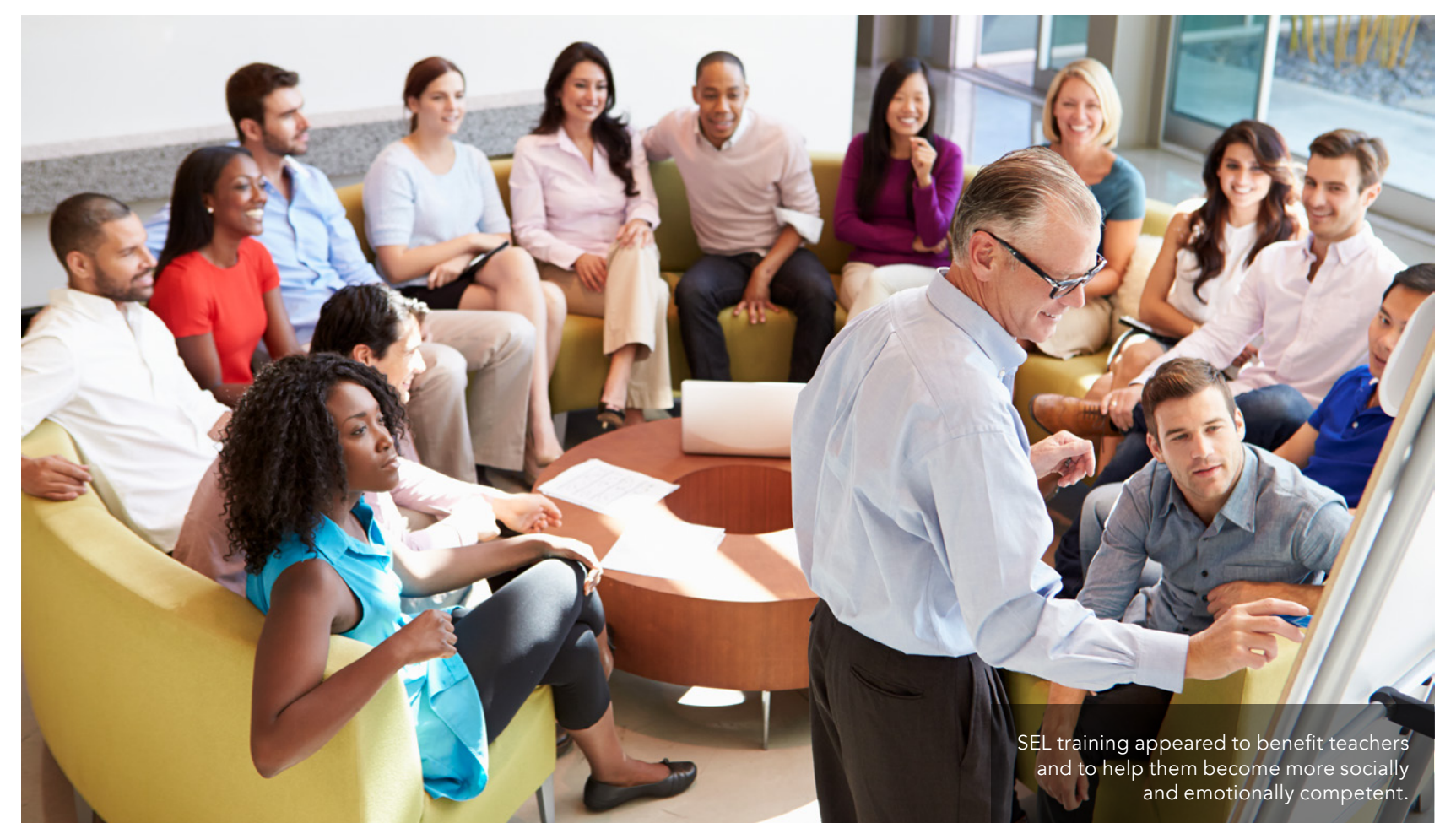

Articles in mainstream publications have also been published, to share the data with a lay audience.

The four-day TET programme was organised in two parts within a six-mo period. To examine the sustainability of the studied TET skills, the teachers' answers to the questionnaire were investigated using the Dealing with Challenging Interaction (DCl) method which was developed to capture teachers' styles of interaction in typica situations at work. Respondents were asked to

sentences how

they would react

to a challenging

event, such as a

confrontation with a

pupil. Investigating

both LQ and TET gave more rigorous and convincing information about the development of teachers' social and emotional learning because the effects of both interventions were quite similar.

The results of the analysis of both LO and TET workshops showed that SEL training appeared to benefit teachers and to help them became more socially and emotionaly competent. This undoubtedly has positive effects on the difficult to account for how cultural and language differences might have had an additional effect on the results (instead trainers and other experts, the team's investigations were successful.

\section{THE FUTURE}

It is hoped that SEL will become part of education policy globally. In Finland, SEL is already part of the new nationa curriculum. However, elsewhere, the to adjust their teaching practices and

hose teachers have participated teachers have not. Such knowledge training programmes.

The results of the present studies, however, indicate that even a relatively short-term, low-cost intervention in teachers' SEL is worthwhile. Successful SEL enables teachers and their studen ts to face challenges and promote wellbeily Lide and outside school more collaborate and develop social and

Socially and emotionally competent teachers are role models will be increasingly will be increasingly
important as important as
globalisation takes hold. Teachers who have

Teachers who ha
undergone SEL
continuing teacher training, such as for their students.

to be fully on board with the theories of SEL and its benefits. Undergoing SEL training as part of teachers' professional development may not necessarily translate into practice and there is still a lack of knowledge about how SEL is used in the classroom setting. up assessment of teachers who have undergone continuing teacher training in SEL at a later date. It would also be and to compare those students could be used to inform future SEL Future research could focus on follow-
LQ workshops, are likely to be able to contribute to this learning by creating enthusiasm and enjoyment in learning and understanding the dynamics of conflicts in the classroom. Socially and emotionally competent teachers are also role models for their students, who will subconsciously learn how to recognise and manage emotions and needs, how to promote happy relationships and respectful ways.

\section{Behind the Research}

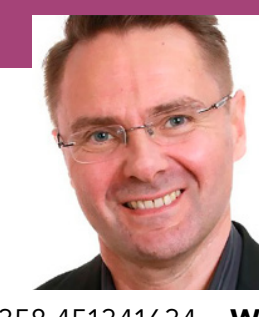

E: markus.talvio@helsinki.f W: Exw.lqevalution.com W: www. in www.linkedin.com/in/markus-talvio-65609818

\section{$\left(\begin{array}{l}\Rightarrow \\ \Rightarrow\end{array}\right) \begin{aligned} & \text { Prof Kirsti } \\ & \text { Lonka }\end{aligned}$}

n 12 w: www.kirstilonka.f @KirstiLonka @ @KirstiLonka f Kirsti Lonka

\section{Research Objectives}

Dr Talvio and Prof Lonka developed methods to investigate teachers' own social and emotional learning, which is crucial when teaching students.

\section{References}

Talvio, M. (2014). How do teachers benefit from training on interaction skills? Developing and utilising an instrument to evaluate teachers' social and emotional learning Helsinki: Helsingin yliopisto. - Talvio, M., Hietajärvi, L., Matischek-Jauk, M. \& Lonka, K. (2019). Do Lions Quest (LQ) workshops have systematic impact on teachers' social and emotiona learning (SEL)? Electronic Journal of Research in

Educational Psychology, 17(2), 465-494.

-Talvio, M. \& Lonka, K. (2019). How to Create a flourishing Classroom? An Intervention Protocol for Enhancing Teachers' Social and Emotional Learning In: Van Zyl, l., Rothmann Sr., S. (eds). Positive psychological Intervention Design and Protocols for Multi-Cultural Contexts. Springer, Cham. - Talvio, M., Matischek-Jauk, M., Hietajärvi, L. \& Reicher, H. (2017). How Do Austrian Teachers Benefit from 9-10, 802-809.

- Talvi, M. Be. M, Litmanen, T. \& Lonka, K. (2016). The Benefits of Teachers' Workshops on Their Social and Emotional Intelligence in Four Countries. Creal Education, 7, 2803-2819. Available at: https://doi. org/10.4236/ce.2016.718260

- Talvio, M., Berg, M., Komulainen, E. \& Lonka, K. (2016). Exploring the coherence of the goals achieved through a youth development programme. Procedia: Social and Behavioral Sciences, 217, 469-476.

-Talvio, M., Berg, M., Ketonen, E., Komulainen, E. \& Lonka, K. (2015). Progress in Teachers' Readiness to Promote Positive Youth Development among Students during the Lions Quest Teaching Workshop. Journal of Education and Training Studies, 3, 1-13. Talvio, M. \& Lonka, K. (2013). International variation perceiving goals of a youth development programm Behavioural Sciences, 6(3), 1057-1065.

\section{Detail}

Dr Markus Talvio

Eläinlääkärinkatu 7 b 38

00580 Helsink

Mio Psychology and a teacher trainer from University of Helsinki, Finland. He has gathered experience from various jobs in the private and public sector. Well-being in learning has been

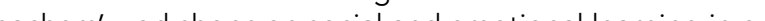
ten different countries.

Kirsti Lonka, PhD is Professor of Educational Psychology and a teacher trainer from University of Helsinki, Finland. She is NWU, South Africa. Prof Lonka has published morus Area, refereed journal articles and several books. She is a popular keynote speaker around the world.

Funding

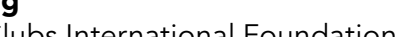

Collaborators

\section{Personal Response}

What are the key requirements for developing SEL skills and competencies in teachers?

II In modern educational psychology SEL provides an important approach for the development of pedagogy and overall well-being at school. Therefore, studying SEL should be the standard for all teachers and it should 